\title{
Application of problem-based learning in instrumental analysis teaching at Northeast Agricultural University
}

\author{
Shuang Gao ${ }^{1} \cdot$ Yuxin Wang ${ }^{1} \cdot$ Bin Jiang ${ }^{1} \cdot$ Ying Fu $^{1}$ \\ Published online: 13 April 2018 \\ (C) Springer-Verlag GmbH Germany, part of Springer Nature 2018
}

\section{Introduction}

Problem-based learning (PBL) was introduced to an instrumental analysis course, which was a public basic course for students from non-chemistry majors at Northeast Agricultural University. Some principles and processes in the practice of PBL are discussed, as well as investigations into the teaching effect of PBL. The study indicated that although there were some negative evaluations, the vast majority of students in the PBL group were willing to accept the PBL method. Compared with traditional teaching methods, PBL could significantly improve the comprehensive ability and motivation of students.

Owing to the rapid development of analytical science and technology, new processes and methods have hastened the development of instrumental analysis courses. Instrument analysis has been widely used in various fields, such as pharmaceuticals, life sciences, environmental science, agricultural science, and food science, as a means of modern analysis and testing. Hence, an instrumental analysis course is regarded as one of the important basic courses for students in nonchemistry majors in many agricultural universities. Because students in instrument analysis courses are required to possess knowledge of mathematics, physics, chemistry, precision instruments, and other multidisciplinary content, they have often experienced difficulties in the learning process, which has resulted in low learning efficiency. The main limitation in the teaching of an instrument analysis course for undergraduate students is that most teachers follow traditional lecturing methods. In traditional methods, teachers often take the central role in class, while students assume a passive role. Students only passively accept knowledge from teachers and

Ying Fu

fuying@neau.edu.cn

1 College of Science, Northeast Agricultural University, Harbin, China find it difficult to develop critical thinking and understanding in these classrooms $[1,2]$. Therefore, there is an urgent need to explore teaching methods for instrumental analysis courses and make learning more efficient to meet the requirements of different students.

PBL is considered to be a student-centered teaching method. In PBL, ill-structured problems related to a subject area are often used to provide opportunities for interaction with others, responses to or from others, and problem-solving to help enhance interactions and critical thinking $[3,4]$. PBL is not a new method of advocating education based on experience. In PBL, students work together to solve problems, and they should also analyze their working process to help them learn more actively. It is anticipated that working on real-world problems will help students relate them to their own learning. After PBL was introduced to medical education by Barrows [5], more and more research on PBL was carried out based on this model. In the last 20 years, PBL was adopted in a variety of professional education and training situations [6-8].

It was commonly agreed that problems with multiple answers should be used as a vehicle to start PBL [9-11]. The PBL students were presented with the problem and divided into groups $[12,13]$. Information provided by the teacher was not sufficient to solve the problem and students would be required to think deeply to clarify what the problem was and what they needed to learn to propose a possible solution [14-16]. Students would develop critical thinking and problem-solving skills [17]. PBL could effectively improve the motivation of students and ability to access and process information [18]. Research has suggested that the PBL experience for students might have a positive impact on academic achievement, conceptual development, and attitudes towards science courses [19-22].

In recent years, PBL has been introduced to various chemistry courses, such as analytical chemistry laboratories [23], electrochemistry [24], pharmaceutical chemistry [25], environmental chemistry [26, 27], physical chemistry [28], and medicinal chemistry [29]. Some courses were aimed at 
chemistry majors and others were specific courses for environmental, pharmacy, and other specialized students. Most studies were limited to the application of PBL to courses with a certain specialty and, as a consequence, most reported results similar to those obtained for vocational training or professional skills training. At the same time, the small sample size in specialized courses, generally 10 to 50 students, might lead to a conclusion with less universality. This study focused on the application of the PBL method to an instrumental analysis course, which was a public basic course for students from many specialties at an agricultural university. The sample size was more than 100 students. The study aimed to discuss principles and processes in the practice of PBL. The attitudes of students to PBL and teaching effects were also investigated.

\section{Methodology}

This study introduced PBL to students taking an instrumental analysis course. All students were in their third semester and non-chemistry majors at the Northeast Agricultural University in China. Research lasted for $16 \mathrm{wk}$, interspersed with conventional lectures. An experimental class of 142 students, named the PBL group, and a traditional class of 116 students, named the control group, were investigated. Students in the PBL group were divided into small groups of three to five students and followed the PBL approach, whereas those in the control group were taught the instrumental analysis course by traditional teaching methods. Specific problems were developing according to topics typically covered in the instrumental analysis course and distributed to the PBL groups at the beginning of the semester. In the process, each group organized regular or irregular meetings every 1 or 2 wk and leaders in each group were required to keep a detailed record of each meeting. Teachers should carefully read the minutes of the meetings to assess the progress of the students. In addition, teachers should attend meetings at least once a month. Meetings could take various forms, including webinars.

The PBL procedure followed the steps outlined below:

Step 1 Grouping and task assignment This step should be implemented at the beginning of the semester.

Step 2 Analyze and clarify the problem At this stage, students should collect relevant information from various sources to analyze and clarify the problem. The aim of this step is for students to realize what they need to learn. This step lasts from the 2 nd to the 5 th week of the semester.

Step 3 Suggest possible methods From the 7th to the 10th week, students are encouraged to indicate possible methods to solve the problem. Oral and written reports on the introduction and theory of possible analytical methods should be submitted in the middle and at the end of this stage, respectively.

Step 4 Improvement of the details Students should work on the details of the project, commonly including the preparation and pretreatment of samples, specific steps for determination, conditions and precautions, and methods of data processing. This step lasts for 3 wk.

Step 5 Summarize and evaluate At the end of the semester, each group should submit its final report on how to solve the problem. A PowerPoint presentation or other document is required to summarize the project. In addition, the working process for solving the problem should be described in the report. The performance of each group should be evaluated by both the teacher and students in other groups.

\section{Application of PBL in an instrumental analysis course}

\section{Guided design and practice with the online learning platform for PBL}

In the PBL study, exploration was a necessary process to solve the problem [9]. The curriculum should be planned in a spiral manner, so that students build upon what they have already learned continually. Students are not able to implement learning activities without appropriate learning resources. Therefore, the acquisition of learning resources was an important part of the students being able to solve the problem. With the purpose of taking advantage of network resources as much as possible, an online learning platform for PBL was built (http://202.118.167.91/dahua/kcsz/yqfxgg/default.asp). By using the online learning platform, students could collect, analyze, organize, and process relevant materials according to their individual learning goals and tasks. They could use the platform to visit commonly used free library, database, and literature searching URLs, as well as find related links for important test centers and well-known chemical websites to obtain the latest information on instrument analysis. An online question and answer system was specially designed to help students solve the problem and provide students with effective online learning guidance. The online learning platform could guide the students to use the network resources more effectively and provide a good interactive platform for study.

\section{Grouping students into teams}

The PBL and control groups were investigated to evaluate the effect of PBL. Students in the PBL group followed the instrument analysis course according to the PBL approach, whereas 
students in the control group were taught the instrument analysis course through a series of lectures.

Students in the PBL group were divided into groups, with generally three to five students in each group. Grouping was based on primary knowledge and learning attitudes, and students at different levels were added to the same group to keep groups heterogeneous, so that students could help and learn from each other [10]. A leader of each group was designated to act as the coordinator and organizer. Generally, the leader should organize regular or irregular meetings, according to the learning needs of their own group. Necessary materials for learning should be provided by teachers at the start of PBL.

\section{Definition of learning goals and problems}

The problem and goals of learning should be designed according to the following rule: the problem must be clear and the results predictable. The difficulty of solving the problem should correspond to abilities of the students. To perform the task, students must seek additional resources and interact with others. A suitable environment should be provided by teachers to help students actively participate in learning activities and try to propose possible solutions. After grouping, students should discuss and analyze the problem, and explicitly state the task and evaluation criteria. The key to PBL was to design a suitable problem scenario, which was best related to the real lives of students. At the same time, the problem should be open-ended with no fixed answer to be conducive to cultivating creative thinking. In the initial trial of PBL, some problems were not sufficiently relevant to real life, so students became disinterested. After investigation, we changed the problems. Now, most problems are selected from real-world examples, such as how to determine the content of vitamin $\mathrm{B}_{2}$ in energy drinks, how to determine pesticide residues in vegetables, or how to analyze the quality of water in the local Songhua river. These problems were hot topics in real life, so it was easier to evoke interest and enthusiasm from the students. While working on the problems, students uncovered what they really needed to know step by step. For example, if they were trying to solve the problem of how to analyze the quality of water in Songhua river, they found that they had to clarify some points, such as evaluation standards, appraisal contents, common pollutants in river, methods of sampling, and pretreatment methods, before they could develop solutions. In this way, the students' thinking and understanding would gradually deepen, which was beneficial for completing the course. As a result of a real-life story that fake wine led to blindness, we proposed a unit problem for students, Analysis of commercial Chinese spirit components, with the following syllabus: (1) What are the main ingredients in spirits? What is the national standard on the quality of spirits? (2) At present, which methods can be used to analyze spirit components? (3) What is the principle method of spirit analysis by gas chromatography (GC)? (4) What is the basic structure of the gas chromatograph? Which detector should be chosen? (5) Which chromatographic and operating conditions are required? (6) What factors influence column performance and resolution? (7) What methods are available for qualitative analysis in this case? (8) What methods are available for quantitative analysis in this case? (9) What is the scope of GC? By following the syllabus, students uncover relevant knowledge of GC step by step.

\section{The Role of Teachers in PBL}

In PBL, the teacher's role was greatly changed compared with that in the traditional model. PBL instructors should emphasis the student's central position in learning, and act more like a facilitator and observer than a teacher [15]. The teacher should provide the necessary materials and guidance to facilitate students to learn the vast amount of knowledge necessary for solving the problem. In the early stages of the course, students always asked: How does this course relate to my own major? What do you want us to learn from this course? To ease the student's concerns, the teacher should introduce some applications of the instrument in a related subject, so that the students can understand how the instrumental analysis course relates to their professional course. For example, the determination of $\mathrm{N}, \mathrm{P}$, and $\mathrm{K}$ in soil samples; the determination of $\mathrm{Na}^{+}$ and $\mathrm{Cu}^{2+}$ in water; the determination of glutathione $\mathrm{S}$ transferase (GST) activity in biological cells; and the determination of aspirin content in the drug were appropriate examples for students that were closely related to their professional courses. Teachers should combine knowledge with practical problems to improve the students' interest in learning. They should encourage students to get involved in the learning process, and provide suitable suggestions on cooperation strategies, communication skills, the definition of roles, and competition with other groups. Teachers need to give appropriate explanations and guidance, so that students understand how to use the existing equipment and how to find materials related to the task. Under these conditions, students can creatively solve the problem with help from each other. Teachers should estimate the learning efficiency and obtain feedback from students. Teachers should rapidly master the situation for students; they need to discover and mark changes in students during the learning process, with respect to interest and motivation, and make necessary adjustments to the groups. The entire situation will influence the grades of the students. Grades usually consist of two parts: team scores and individual scores. Both parts were evaluated by the teacher and group members. Evaluation from different sources reflects the actual performance of students more accurately.

To perform their duties well, the PBL teachers should follow some basic principles. In the early stage, the teacher should promote discussion and insure students are focusing 
on suitable aspects of the problem. They should help direct the students to work in the right way to generate and deal with information. This should be achieved by asking questions and examining summaries. Adequate knowledge of and familiarity with the students are necessary for teachers to perform their duties. They should steer students in the right direction to goals that are achievable. If the students try to work towards a goal that is too comprehensive or spend too much time on irrelevant aspects of the problem, the teachers must guide them back in the right direction. The tutor should ask questions to make sure students reach an adequate depth of analysis of the problem, not just the use of superficial knowledge and explanations.

If there is conflict within the group or they make mistakes, the teacher should help the group to see the problem - not just solve the problem for the students. They could use appropriate questions to guide students to realize their own mistakes. For example, if students ignore the design of the standard curve, they could be asked how to convert the peak area or absorbance to concentration. If the students ignored the procedure of pretreatment, they could be asked what sample can be directly analyzed by liquid chromatography and can samples that do not meet the requirements be analyzed. If students ignore sampling processing, they could be asked how to ensure that the results can represent the true content in the sample.

\section{Changing role of students in the PBL teaching method}

PBL is a student-centered instructional strategy that is considered to be helpful to improve interactions and critical thinking of students. PBL students are split into groups of three to five people and a problem is given to the students before they are taught. After the problem is given, the PBL group should discuss and analyze the problem. The problem is solved based on notes from the teacher that highlight and focus on the important concepts. Getting additional information from other sources, such as the internet and any articles or books related to the course, is also encouraged. Students can obtain relevant information by consulting books on the subject in the library, looking up technical literature or articles in databases, or by using a search engine to search in the internet. In addition to the project proposal, the groups are required to prepare one or two oral progress reports. Through self-directed learning in groups, students might improve their abilities to express and process information by explaining their own understanding of the problem or by generating useful knowledge through group discussions [11]. It could be helpful for students to overcome their fears by realizing that others also face difficulties in learning. The sense of accomplishment generated by answering each other's questions encourages further participation and develops positive interdependence and trust. Each group should submit a written report on the learning situation at the end of the semester.

\section{Teaching effect}

Differences between PBL and traditional teaching methods are shown in Table 1. The attitude of students towards PBL and negative evaluations of PBL are shown in Tables 2 and 3, respectively. The investigation indicated that most of the students in the PBL group were willing to accept the teaching method, despite some students criticizing PBL for being a time-consuming process, with a heavy workload, too much vague information, and a lack of trust. Results showed that PBL had a great effect on the use of analytical methods and instruments. Communication between students enhanced their motivation to learn. Improved motivation resulted in a significant increase in the number of participants participating in various projects, such as student innovation practical training on pesticide residue analysis, food analysis, and other experiments. Students with specialties in animal medicine, biological engineering, and environmental science considered that through this PBL course, their ability to review and analyze the literature and analytical skills were improved. The improvements in scientific research abilities were fully reflected in their graduation theses.

To evaluate the effects of the PBL model in an instrumental analysis course, the authors collected the final scores of one experimental class (PBL group) and one non-experimental class (control group), and analyzed the results with SPSS 18, as shown in Table 4. Data in Table 4 showed that the PBL group achieved higher mean scores than those in the control group, which meant that the PBL group was more effective than the control group. Thus, PBL is an effective model for an instrumental analysis course.

\section{Current difficulties in PBL}

\section{Difficulty for students to obtain information effectively}

The ability to obtain and process information is a basic ability that students must possess to follow PBL. In this era of information explosion, it is necessary for students to master modern science and technology to obtain, process, and transfer information effectively. In the context of an informationbased campus, students can obtain information in various ways, such as from books in the library, literature in databases, papers on the internet, or community and discussion groups on the internet. Although the hardware available on campus could meet the demand, some students, especially 1st-year students, lacked relevant abilities. 
Table 1. Comparison and analysis of PBL and traditional teaching methods

\begin{tabular}{|c|c|c|}
\hline Comparative point & PBL & Traditional teaching \\
\hline Participation degree & participation span wider; participation depth deeper & $\begin{array}{l}\text { participation span more limited; participation depth } \\
\text { limited }\end{array}$ \\
\hline $\begin{array}{l}\text { Individual } \\
\text { responsibility }\end{array}$ & strong & weak \\
\hline $\begin{array}{l}\text { construction of } \\
\text { professional } \\
\text { knowledge }\end{array}$ & understanding of knowledge is more accurate & only recitation; understanding inaccuracies \\
\hline $\begin{array}{l}\text { Diversity of } \\
\text { knowledge }\end{array}$ & $\begin{array}{l}\text { students obtain more resources through the network environment } \\
\text { and have more dissimilar knowledge }\end{array}$ & $\begin{array}{l}\text { resources are limited in a traditional school classroom } \\
\text { environment and team members have similar } \\
\text { resources }\end{array}$ \\
\hline $\begin{array}{l}\text { Communication } \\
\text { skills }\end{array}$ & $\begin{array}{l}\text { PBL provides more opportunities for communications; group members } \\
\text { gain better communication skills }\end{array}$ & lack of communication skills \\
\hline $\begin{array}{l}\text { Explaining the } \\
\text { problem }\end{array}$ & easier to show the overall picture of the question to cooperation group & $\begin{array}{l}\text { teachers find it hard to show the overall picture of the } \\
\text { problem away from real life }\end{array}$ \\
\hline $\begin{array}{l}\text { Development of } \\
\text { problem-solving } \\
\text { skills }\end{array}$ & PBL helps students improve their problem-solving skills & the ability to solve problems is lacking \\
\hline $\begin{array}{l}\text { development of } \\
\text { self-directed } \\
\text { learning }\end{array}$ & more willing to learn by themselves & relies heavily on guidance from the teacher \\
\hline
\end{tabular}

\section{Lack of student participation in group activities}

Compared with traditional learning methods, more interaction is needed in PBL. Favorable interactions help to solve difficulties encountered in the learning process and establish the collective concept, but some students are not active enough in group discussions.

\section{Inflexibility of teachers in the new role}

The role of the teacher changes greatly in PBL, compared with that in the traditional classroom. Some teachers felt puzzled by the new role. By misunderstanding the new role, some teachers acted too passively. They followed the studentcentered principle so thoroughly that they became completely uninvolved, without providing the necessary materials and guidance. In fact, the teacher is an important component of the group. Teachers should guide the process and content to help students to learn in groups. In addition, it was difficult for teachers to guide all groups in detail. Graduate students working as teaching assistants would effectively improve this problem. Unfortunately, there were no such assistants in our case.

Table 2. Attitude of students towards PBL $(n=142)$

\begin{tabular}{llllll}
\hline Attitude & Enjoy & Like & Neutral & Dislike & Greatly dislike \\
\hline Numbers & 41 & 73 & 11 & 6 & 1 \\
Percentage & 28.9 & 51.4 & 7.7 & 4.2 & 0.7 \\
\hline
\end{tabular}

\section{Conclusion}

Instrumental analysis courses in universities are often taught by traditional approaches that are often teacher-centered. This study introduced a new teaching approach (PBL) for an instrumental analysis course. The attitude, performance, degree of acceptance, and learning effects of students towards PBL were investigated. Compared with the traditional teaching model, PBL had the potential to provide motivation for students. It showed advantages in many aspects, such as degree of participation, individual accountability, construction of professional knowledge, diversity of knowledge, improving problem-solving skills, and self-directed learning; thus PBL could significantly improve the comprehensive ability of students. PBL is a new teaching approach that has proven to be suitable for the instrumental analysis course in this study. Limitations of this study mainly lie in the small number of students and short study period, which might reduce the universality of the results. This study can be improved and

Table 3. Students' negative evaluation on PBL $(n=142)$

\begin{tabular}{lll}
\hline Students' negative evaluation on PBL & Number & Percentage \\
\hline Time-consuming & 58 & 40.8 \\
Difficulty in understanding the key point & 47 & 33.8 \\
Worry about the final performance & 66 & 46.5 \\
Had difficulty obtaining enough information & 32 & 22.5 \\
Puzzled by vague information & 54 & 38.0 \\
Difficult to reach an agreement & 47 & 33.1 \\
Confused, puzzled, stressed, difficult to speak up & 32 & 22.5 \\
\hline
\end{tabular}


Table 4. Comparison of mean scores of different groups in exams

\begin{tabular}{llllll}
\hline Group & $n$ & Mean & SD & Standard error & Skewness \\
\hline PBL & 142 & 83.8521 & 8.50944 & 0.71410 & -0.994 \\
Control & 116 & 75.6810 & 12.96457 & 1.20373 & -0.621 \\
\hline
\end{tabular}

perfected in future research by choosing a larger sample and extending the learning cycle. Moreover, there was no laboratory support for students to develop and modify their scheme. Although the task for students was only to build a possible plan to solve the problem without testing and verifying the solution, it would be helpful for learning if they could work in a laboratory. Further studies on instrumental analysis courses may focus on the effect of longer term PBL on the attitude, motivation, and satisfaction of students.

Acknowledgements This paper was financially supported by the Education Sciences Planning Project of Heilongjiang Province (GJC1316059), the Education Sciences Planning Project of Heilongjiang Province (GJC1215009), the Research Project on Teaching Reform of Degree and Graduate Education of Heilongjiang Province (JGXM_HLJ_2015038), and Da Bei Nong Educational Scholar Project (XBJJY17018).

\section{Compliance with ethical standards}

Conflict of interest The authors certify that they have no conflict of interest in the subject matter or materials discussed in this manuscript.

Human and animal studies No animal or human subject was used in the work related to this manuscript.

\section{References}

1. Billings DM, Halstead JA. Teaching in Nursing: A Guide for Faculty. 2rd ed. St. Louis: Elsevier Saunders; 2005.

2. Wood DF. ABC of learning and teaching in medicine: problembased learning. BMJ-Brit Med J. 2003;326:328-30.

3. Belland BR, French BF, Ertmer PA. Validity and problem-based learning research: a review of instruments used to assess intended learning outcomes. Interdiscip J Problem-Based Learn. 2009;3:5989.

4. Colliver JA. Effectiveness of problem-based learning curricula: research and theory. Acad Med. 2000;75:259-66.

5. Barrows HS. Problem-based learning in medicine and beyond: a brief overview. New Directions for Teaching and Learning. 1996;1996:3-12.

6. Wilkerson L, Gilselaers H. Bringing problem-based learning to higher education: Theory and practice. San Francisco: John Wiley and Sons Inc.; 1996.

7. Shin JH, Haynes RB, Johnston ME. Effect of problem-based, selfdirected undergraduate education on life-long learning. Can Med Assoc J. 1993;148:969-76.

8. Wells M, Clougherty R. Use of Wikis in chemistry instruction for problem-based learning assignments: an example in instrumental analysis. J Chem Educ. 2008;85:1446-8.
9. Dahl B. What is the problem in problem-based learning in higher education mathematics? Int J Eng Educ. 2017;4:1-14.

10. Weiss DM, Belland BR. PBL group autonomy in a high school environmental science class. Tech Knowl Learn. 2017;1:1-25.

11. Gallagher SA, Sher BT, Stepien WJ, Workman D. Implementing problem-based learning in science classrooms. Sch Sci Math. 1995;95:136-46.

12. Schwartz P, Webb G, Mennin S. Problem-based learning: case studies, experience and practice. 1st ed. Abingdon: Routledge; 2001.

13. Barell JF. Problem-based learning: an inquiry approach. 2nd ed. Thousand Oaks: Corwin Press; 2007.

14. Woods DR. Problem-oriented learning, problem-based learning, problem-based synthesis, process oriented guided inquiry learning, Peer-led team learning, model-eliciting activities, and project-based learning: What is best for you? Ind Eng Chem Res. 2014;13:533754.

15. Larive CK. Problem-based learning in the analytical chemistry laboratory course. Anal Bioanal Chem. 2004;3:357-9.

16. Etherington MB. Investigative primary science: a problem-based learning approach. Aust. J Teach Educ. 2011;9:36-57.

17. Barbara JD, Susan EG, Deborah EA. The power of problem-based learning. 1st ed. Sterling: Stylus Publishing; 2001.

18. Albanese M. Problem-based learning: why curricula are likely to show little effect on knowledge and clinical skills. Med Educ. 2000;34:729-38.

19. Mohd-Yusof K, Helmi S, Jamaludin M, Harun N. Cooperative problem-based learning: a practical model for typical course. Int J Emerg Technol Learn. 2011;3:12-120.

20. Nookhong J, Wannapiroon P. Development of collaborative learning using case-based learning via cloud technology and social media for enhancing problem-solving skills and ICT literacy within undergraduate students. Procedia Soc Behav Sci. 2015;174:2096101.

21. Flynn AB, Biggs R. The development and implementation of a problem-based learning format in a 4th-year undergraduate synthetic organic and medicinal chemistry laboratory course. J Chem Educ. 2012;89:52-7.

22. Tandogan R, Orhan A. The effects of problem-based active learning in science education on students' academic achievement, attitude and concept learning. Eurasia J Math Sci Tech Educ. 2007;3:71-81.

23. Günter T, Akkuzu N, Alpat Ș. Understanding 'green chemistry' and 'sustainability': an example of problem-based learning (PBL). Some parts of this study were given as an oral presentation at the '1st International Green Chemistry and Sustainable Technologies' Congress. 2015: 500-520

24. Günter T, Alpat SK. The effects of problem-based learning (PBL) on the academic achievement of students studying 'Electrochemistry'. Chem Educ Res Pract. 2017;18:78-98.

25. Gu XL, Song XF, Sun HW, Dong MJ, Li J, Liu GY, et al. Teaching reform of pharmaceutical chemistry with PBL method. Indian J Pharm Educ. 2016;50:530-3.

26. Jansson S, Söderström H, Andersson PL, Nording ML. Implementation of problem-based learning in environmental chemistry. J Chem Educ. 2015;92:2080-6.

27. Gao S, Hilts RW, Ross MS, Styler SA. Particulate matters: studentled air quality research in the third-year environmental chemistry classroom and the field. Anal Bioanal Chem. 2018; https://doi.org/ 10.1007/s00216-018-0972-3.

28. De los Santos DM, Montes A, Sanchez-Coronilla A, Navas J. SolGel application for consolidating stone: an example of projectbased learning in a physical chemistry lab. J Chem Educ. 2014;91:1481-5.

29. Ravari EMH, Nouhi E. Problem-based learning in medicinal chemistry laboratory from pharmacy students' perspective. Indian J Pharm Educ. 2014;48:4-8. 


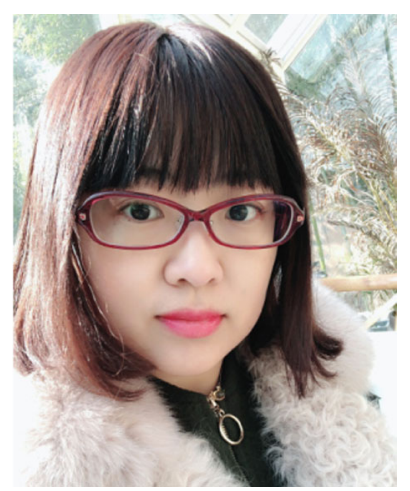

pesticide.
Shuang Gao is an assistant professor in the Department of Applied Chemistry at Northeast Agricultural University in China. She received her Bachelor of Science degree in Chemistry from Harbin Normal University and a $\mathrm{PhD}$ in Agriculture from Northeast Agricultural University. Her multidisciplinary research encompasses areas such as instrumental analysis, analytical chemistry, and general chemistry, with a focus on molecular design and residue analysis of

Yuxin Wang is a chemistry faculty member at Northeast Agricultural University in Harbin, China. She received a $\mathrm{PhD}$ in Food Science and Engineering. Her research involves analytical chemistry and food science. She began working at Northeast Agricultural University in 2004.

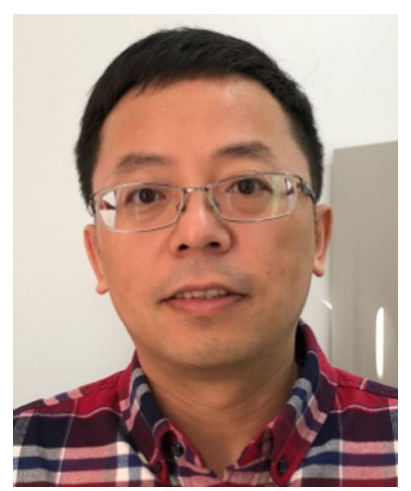

Bin Jiang is an assistant professor in the Department of Applied Chemistry at Northeast Agricultural University in China. His multidisciplinary research encompasses areas such as analytical chemistry and food chemistry, with a focus on isolation and purification of protein and other biomolecules.

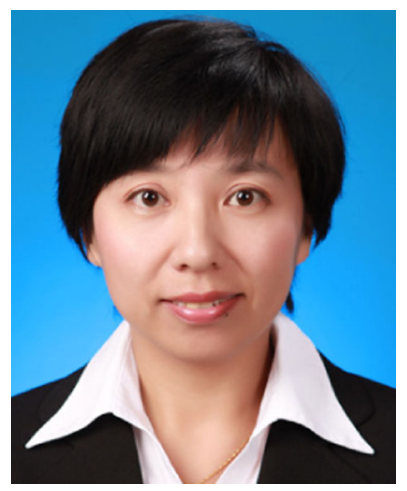

Ying Fu obtained her $\mathrm{PhD}$ in Chemical Engineering and Technology from Harbin Institute of Technology in China. Her group's research focuses on the relationship between designs, synthesis, and structure effect of pesticide, especially in construction of the QSAR model of pesticide structure and its protective activity. 